\title{
HERMAFRODITISMO EN MOLUSCOS AULACOMYA ATER (MOLINA) Y ENOPLOCHITON NIGER (BARNES)
}

VICTOR ISHIYAMA CERVANTES

BETTY SHIGA OSHIGE

En nuestro país no se ha reportado ningún caso de hermafroditismo en moluscos con sexos separados (dioicos, posiblemente debido a los pocos trabajos que se realizan utilizando métodos histológicos, técnica que permite determinar con mayor precisión los estadios de madurez gonadal, facilita la observación microscópica de las características de las células sexuales y permite detectar los posibles casos de hermafroditismo que pasan desapercibidos con las observaciones macroscópicas.

Aulacomya ater es un molusco, pelecípodo de la familia Mytilidae que presenta sexos separados: la gónada se halla difusa en el manto, mesosoma y masa visceral: durante la madurez gonadal, el color de la gónada varía de matices de color beige en los machos y de matices del color morado en las hembras.

Durante el tiempo que duró la investigación sobre la reproducción de $A$. ater fueron colectados al azar un promedio mensual de 40 ejemplares de Bahía Independencia ( $76^{\circ} 08^{\prime} \mathrm{LO}-14^{\circ} 15^{\prime} \mathrm{LS}$ ); en el muestreo correspondiente a diciembre de 1991 se encontró un especimen hermafrodita con características externas de masa visceral moteado, un lado del manto con características de una hembra y el otro lado con características del macho, esto es detectable sólo en individuos maduros; corroborado histologicamente, presentó un predominio de folículos llenos de oocitos maduros y entre los espacios interfoliculares, se observó presencia de cúmulo de espermatogonios y espermatozoides. El especimen presentó una longitud de $60.35 \mathrm{~mm}$ y peso total de $20.4 \mathrm{~g}$.

Los reportes sobre hermafroditismo en mitílidos son escasos, como los reportados en América del Norte en Mytilus californianus (Yung, 1941, 1951), en Francia en Mytilus edules (Lubet, 1959) y en Puerto Deseado, Argentina en Aulacomya ater (Vinuesa, 1977).

Enoplochiton niger es un molusco poliplacóforo de la familia Chitonidae; son de sexos separados, carecen de dimorfismo sexual, la gónada es un saco único localizado en la parte dorsal del animal, cuyo color varía desde el translúcido (indiferenciado) hasta el blanco lechoso (maduro) en los machos y desde el translúcido (indiferenciado) hasta el verde oscuro (maduro) en las hembras. Durante el estudio sobre la reproducción de $E$. niger, de noviembre de 1990 a noviembre de 1991 , se colectaron al azar de la playa de San Bartolo, Lima $\left(76^{\circ}\right.$ $47^{\prime}$ LO - $12^{\circ} 23^{\prime} \mathrm{LS}$ ), un promedio mensual de 21 ejemplares: durante el análisis histológico de las gónadas detectamos dos cjemplares hermafrodita: a) uno en el mes de marzo midió $55.5 \mathrm{~mm}$ de longitud, con un peso total de $8.3 \mathrm{~g}$ y el peso de la gónada $0.1 \mathrm{~g}$, con características externas de gónada masculina; histológicamente con un predominio de espermatogonias y espermatozoides y una parte reducida con oocitos en madurez y b) el segundo ejemplar fue detectado en abril. tenía una longitud de $49.0 \mathrm{~mm}$, peso total de $6.1 \mathrm{~g}$ y el peso de la gónada $0.2 \mathrm{~g}$. las características de la gónada era para hembra: la estructura histológica de la gónada con un predominio femenino con oocitos maduros en desove y la zona interna lateral reducida de gónada masculina con espermatogonias y espermatozoides. E1
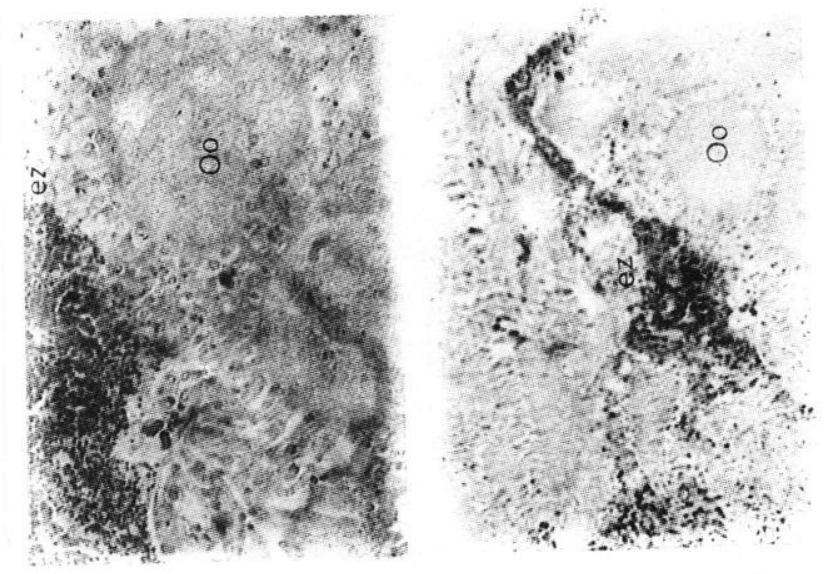

Fig. 1: Corte Histologico de Gonada de E. niger bermafrodita Oo: Ovocito maduro, ez: espermatozoide po: prolongaciones del Oocito A: 40x B: $80 x$ C: $160 x$

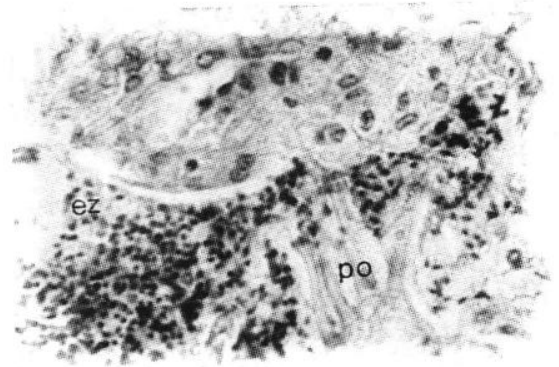


especimen reportado corresponde a la zona de la playa de San Bartolo. (Fig. 1) (Ishiyama, et.al., en prensa).

\section{REFERENCIAS BIBLIOGRAFICAS}

ISHIYAMA. C. V., SHIGA 0. B. y HUAMAN, M. P. 1993. Reproducción en Enoplochiton niger (Mollusca. Poliplacophora) de la playa San Bartolo, Lima. Boletin de Lima (en prensa).

LUBET, P. 1959. Recherches sur le cycle sexual et l'emission des gamétes chez les Mytillidés et les Pectinidés. Rev. Trav. Inst Peches Matim., 23: 339 -548

VINUESA, J. H. 1977. Sobre un caso de hermafroditismo en la cholga Aulocomya ater (Molina). Physis. Secc. A Buenos Aires, 37, 93: 63-65.

YOUNG, R. T. 1941. A hermaphroditie Mytilus. Nautilus 54: 90-91.

YOUNG, R.T. 1951. Another Mytilus hermafrodita. Nautilus 64: 105 